\title{
Using Belief Functions to Forecast Demand for Mobile Satellite Services
}

\author{
Peter McBurney and Simon Parsons \\ Intelligent Systems Applications Group, \\ Department of Electronic Engineering, \\ Queen Mary \& Westfield College, \\ University of London, \\ London E1 4NS, UK \\ $\{\mathrm{p} \cdot \mathrm{j} \cdot \mathrm{mcburney}, \mathrm{s} \cdot \mathrm{d} \cdot \mathrm{parsons}\} @ e l e c \cdot \mathrm{qmw}$. ac.uk
}

\begin{abstract}
This paper outlines an application of belief functions to forecasting the demand for a new service in a new category, based on new technology. Forecasting demand for a new product or service is always difficult. It is more so when the product category itself is new, and so unfamiliar to potential consumers, and the quality of service of the product is dependent upon a new technology whose actual performance quality is not known in advance. In such a situation, market research is often unreliable, and so the beliefs of key stakeholders regarding the true values of underlying variables typically vary considerably. Belief functions provide a means of representing and combining these varied beliefs which is more expressive than traditional point probability estimates.
\end{abstract}

\section{Introduction}

This paper is concerned with forecasting demand for a new telecommunications service-global mobile satellite services (GMSS). Companies intending to provide these services will be offering services in a new market category to new groups of customers $[5,44,54]$. As will be seen, forecasting demand for new technologies and services in new categories such as this presents both methodological and practical issues. Our contention is that approaches which make use of belief functions have the potential to assist in the resolution of some of these issues, because of their allowance for imprecision of knowledge, and their ability to coherently combine disparate sources of information. We support this contention by giving a detailed example of the use of belief functions in the area of demand forecasting for GMSS, from the perspective of the second GMSS operator to enter the market.

Belief functions were first introduced by Shafer [80], who himself built on the work of Dempster [16], and was subsequently developed by a number of authors. This development has led to a wide body of work on what has often been called Dempster-Shafer theory. At the time of writing, there are three main schools of thought within this body of work - these are the upper and lower probability model [30], the probability of provability model [73], and Smet's transferable belief model [89]. This paper applies Smets' transferable 
belief model (TBM), and we adopted this because it seems to us to be the most appealing, as well as the most developed, version of the theory. Since our aim in this article is to concentrate on the application of belief functions rather than the detail of the belief fucntions themselves, we have assumed that the reader is familiar with the transferable belief model. Those readers who do not know the model are encouraged to consult $[83,87,89,90]$. Descriptions of other approaches to belief functions and Dempster-Shafer Theory can be found in $[42,28]$, while general introductions can be found in many papers and textbooks, for example [67,79].

The various belief function approaches have been widely applied. Indeed, they have been applied to auditing $[19,82,91,92,94,104]$; to climatology and water resources management $[9,10,55]$; to nuclear power plant control [18]; to information retrieval $[48,74,88]$; to call hand-off in a mobile telecommunications network [103]; to discriminant analysis and pattern recognition $[17,88]$; to systems reliability and fault diagnosis $[84,86,88,111]$; and to inspection of defects in manufacturing processes [108]. To our knowledge, no work has been published which applies the theory to forecasting demand for a new product or service. In addition, although the forecasting model structure outlined below in Section 4 is typical of those adopted by start-up telecommunications companies, we have not seen it described in print before.

This article is structured as follows: Section 2 presents a brief introduction to the Global Mobile Satellite Services industry. Section 3 discusses some of the methodological and practical issues involved in forecasting demand for a new telecommunications service. Section 4 outlines the structure of a forecasting model developed for forecasting GMSS demand, and this model is used as the basis for the application of belief functions presented in Section 5. Finally, Section 6 looks at further work and concludes. The work described in this article has been motivated by consultancy undertaken by the authors for two intending satellite network operators. Forecasting model structures have been vastly simplified here for presentational purposes, and both structures and parameter values have been disguised in order to protect the identities and the commercial information of our clients. We do not believe this necessary simplification and camouflage detracts from the value of the approach demonstrated here.

\section{Global Mobile Satellite Services}

Global Mobile Satellite Services (GMSS) businesses are a new telecommunications service aiming to provide voice and data communications to customers with hand-held mobile devices anywhere on the planet. These services are provided by radio links between the devices and a network of satellites, typically in low-earth (less than 1,500 kilometers above earth) or intermediate orbits (greater than $10,000 \mathrm{~km}$ ). These orbits contrast with the original com- 
munications satellites, introduced in 1965, which operate from geostationary orbits $(35,786 \mathrm{~km})[57]^{1}$

\subsection{The GMSS market}

To an observer standing on earth, a geostationary satellite appears not to move, and so service can be provided to customers within a footprint from one satellite. Thus, a network of geostationary satellites could be launched incrementally, with service progressively switched on in successive world regions. Non-geostationary satellites, however, require multiple, apparently-moving, satellites to provide services to a fixed customer. This means that it is generally not possible to launch commercial services with such satellites until all or most of the satellites in the network have been deployed [6]. Thus, unlike most telecommunications businesses, the vast majority of investment costs-for construction and deployment of the satellites and the ground network-are incurred before the first dollar of revenue can be earnt. This capital investment is of the order of US $\$ 3-5$ billion $[32,33,77,110]$, which means there are few serious intending operators; for this and other reasons, each comprises a consortium of companies and organizations.

The three main companies providing or intending to provide GMSS voice services are listed here in their expected order of entry to the marketplace:

- Iridium (http://www.iridium.com), of Washington, DC, USA, a consortium led by US communications equipment vendor, Motorola, which launched commercial service in November 1998 [34,35].

- Globalstar (http://www.globalstar.com), of San Jose, CA, USA, a consortium comprising primarily of terrestrial mobile communications operators, and including British-American cellular company VodafoneAirTouch and US equipment manufacturer, Qualcomm. Globalstar is expected to launch commercial service in the first quarter of 2000.

- ICO Global (http://www.ico.com), of London, UK, a consortium of fixed and mobile telecommunications operators from around the world, and including Inmarsat, the International Maritime Satellite organization, and US equipment manufacturer, Hughes Aerospace. ICO is due to launch service in the last quarter of 2000.

The three companies have adopted different technological solutions to the design and implementation problems they each face, and have different business models and commercial structures. For example, ICO has elected to deploy satellites in a medium-earth orbit, while both Iridium and Globalstar have opted for low-earth orbit constellations. The lower the orbit of the

\footnotetext{
${ }^{1}$ Satellites are not placed between 1,500 and $10,000 \mathrm{~km}$, in order to avoid the major radiation belts. Descriptions of various proposals for GMSS systems can be found in $[6,20,23,71,96]$, although some of this information is now dated.
} 
satellites, the less the delay callers will experience in speaking on a satelliteenabled call ("propagation delays") [6]. On the other hand, the lower the orbit, the faster the satellite will disappear over the horizon (or be obscured by trees or buildings), and so the greater the likelihood of inadvertent call termination ("dropout") [71,75].

As a second example of design differences, Iridium, unlike either Globalstar or ICO, uses inter-satellite links (so that Iridium's satellites require telecommunications switching capabilities) to transmit calls from the calling party to the earth station nearest the destination party. Globalstar will instead bring calls to earth as quickly as possible and transmit them via the world's public telecommunications networks. ICO will also bring calls to earth as quickly as possible but then transmit them via its own private global network constructed of leased lines [107]. As a consequence of these different approaches to transmission, users of the different networks may experience very different grades of service.

In another example of differences, Globalstar has selected a technological and commercial structure which means that its network is more closely integrated with the various terrestrial cellular networks of its investors and distribution partners than is the case with either Iridium or ICO [23]. This structure provides Globalstar's partners with more control over the nature and deployment of the GMSS service in their territory, but at the expense of the overall consortium being able to offer globally-seamless services, such as uniform prompts for voicemail.

As suggested, these technical and commercial differences impact the levels and nature of service quality experienced by end-users of each service. To a customer of GMSS, the telephone handset - called a user terminal—looks and feels very similar to a terrestrial mobile handset, although both the antenna and the phone itself are larger and heavier in early-generation MSS models than for current terrestrial mobile services. Service will be available, local conditions permitting, almost anywhere on earth. ${ }^{2}$ Despite this wide availability, levels of service quality are likely to be very different from terrestrial cellular. Service will not typically be available indoors, or in the downtowns of major cities (due to satellite invisibility) [33]. As with terrestrial wireless services [7], weather conditions such as rain and snow will impact service availability and quality. Network congestion, call dropout and propagation delay may be noticeable on particular networks or at particular times [71].

\subsection{GMSS services}

The main voice application markets identified by GMSS operators are as follows $[6,32,39]$ :

\footnotetext{
${ }^{2}$ ICO's service will not be available at the poles, and Globalstar's service will not be available in the middle of the oceans.
} 
Enhancements to terrestrial mobile services. Because GMSS provides services to a handheld terminal, an obvious application is the provision of mobile-like services in areas outside mobile coverage. Customers for these services may be both people living outside terrestrial coverage areas and people inside terrestrial coverage areas with a need to travel outside. Even travellers between areas under terrestrial mobile coverage are a potential customer segment for GMSS because of the proliferation of incompatible cellular and personal communications services technology standards around the world.

Fixed-network extension. Large numbers of the world's population live outside the areas covered by terrestrial fixed telecommunications networks, or face long delays in obtaining connection to a fixed network. GMSS provides the opportunity to provide services quickly and relatively easily to such customers. While the vast majority of people living outside the footprint of fixed network services would be unable to afford GMSS services, GMSS operators believe that significant market potential exists in such regions. Examples include the provision of services in developing countries to remote minerals-extraction operations and communityowned payphones to rural villages.

Specialized or niche applications. These include user terminals installed in aircraft, on-board ships or in road and rail transport vehicles, along with remote data sensing devices installed, for example, to monitor pressures and flows on oil pipelines or in remote rivers. Such applications may be aimed at the general public (such as satellite-enabled payphones on trains or in aeroplanes) or at particular business customers (such as terminals installed in freight trucks).

Many of the fixed-network extension and specialized applications may require only limited or no mobility in the user terminal. Accordingly, such applications are commonly referred to as semi-fixed.

GMSS operators will be able to offer both voice and data communications services, but their primary focus to date has been on providing voice services. Several other companies are also preparing to deploy satellite networks but with the key application being data communications. One such company is Teledesic (http://www.teledesic.com), sponsored by Bill Gates, Craig McCaw and the Boeing Corporation, who plan a 288-satellite network for an estimated total capital investment of US $\$ 9-15$ billion $[6,96]$. In addition to these global MSS operators, a number of companies are providing or are preparing to provide services only on a regional basis, for instance in South-East Asia or the Middle East. In North America, one such company already in service is American Mobile Satellite Corporation (AMSC) (http://www . ammobile.com), whose investors include AT\&T. For simplicity of presentation, only the three major GMSS operators are considered further in this article, although all deployed and intending operators need to be considered as competitors in any comprehensive demand forecasting model. 


\section{Forecasting Demand for a New Telecoms Service}

Planning a new telecommunications business, as with planning any new hightechnology business, requires a large number of technical and commercial decisions to be made in advance of launch of service. Many of these decisions depend crucially upon knowing the numbers of customers (what we refer to as "demand") and the patterns of usage of those customers. In the absence of live, operating data, these decisions can only be made on the basis of forecasts of demand and usage.

In a new GMSS operator, market forecasts are used to guide decisions and actions across all areas of the business, to the point where they become, in the words of a former colleague, "the veins of the organization". Three broad groups of "stakeholders" require demand forecasts: engineering design and implementation teams; marketing and commercial development teams; and external entities, such as potential investors, government and security industry regulators, equipment and applications suppliers, and service distribution partners. In another paper [59], we present and contrast the forecasting requirements of these users, and relate their differing needs to the business life-stages of a new telecommunications company.

\subsection{The Challenges of Forecasting Demand}

Traditional methods of forecasting demand - such as time series analysis and econometric modeling, for example [45,51,98] — require historical data on the market concerned or on a closely-related one. Such data is clearly not available for innovative products such as GMSS which, in the language of marketing, define a new market category $[5,44]$. In fact, even when historical data is available, it isn't necessarily a good thing to use it since in turbulent markets, which do not behave exactly as they have in the past, it can inhibit the identification of new opportunities, changes in trends, market discontinuities, and so on [27], actually degrading the quality of the forecast. ${ }^{3}$

The terrestrial mobile communications industry provides a good example of the difficulty of forecasting demand for a new category in a turbulent environment. Public mobile communications services based on cellular technologies were introduced from the early 1980s, starting in Scandinavia and Japan. Services were then launched in North America and elsewhere in Western Europe from the middle of the 1980s and have since been introduced in most countries around the world. The services were completely new to customers, to operators and their distribution channel partners, to equipment vendors and suppliers, and to Government regulators. In addition, the last

\footnotetext{
3 Traditional methods of forecasting have been likened to "looking forward through a rear-view mirror" [43]. Walsham [105], developing 30-year demand forecasts for telecommunications services, regarded the model as "a forum for debate rather than a forecasting tool".
} 
fifteen years have been a period of great change in the telecommunications industry, due to technological innovations, privatization and corporatization of state-owned enterprises, the entry of new competitors to the market and changing customer preferences. As a consequence, forecasting of demand has been a difficult task. The head of forecasting and analysis for the International Telecommunications Union has stated "the mobile communications market has proved to be one of the most dynamic, but also one of the most difficult to forecast, of all the parts of the telecommunications sector. The forecasts produced by equipment suppliers, network operators and by specialist consultancies have consistently underestimated the actual market potential" [41]. Even by 1995, when forecasters had a decade's experience of the rapid growth of demand and the category was no longer new to customers or to operators, forecasts from credible forecasters for world-wide terrestrial mobile customers in the year 2000 - just five years ahead-ranged from 200 million to 350 million customers [41]. Yet even the largest of these may have been under-estimates. In early 1999, a mobile industry technology association forecast that the world-wide demand would 426 million customers by the year 2000 [99].

Since Lancaster $[49,50]$, marketers have viewed a product or service as a bundle of features or attributes. It is these attributes which together form the basis of customer preferences for the product. For telecommunications services, the feature set may include basic technical characteristics of the service (such as propagation delays; likely congestion levels; data communications capacities; and so on); value-added or enhanced features (such as voicemail; call diversion capabilities; conference calling; and so on) and commercial elements (for example purchase and activation arrangements; pricing structures and levels; billing and payment arrangements; and after-sales customer service). Experience within the marketing community has been that demand will often depend crucially on the particular set of features offered, and different customers may exhibit very different preferences for different bundles [38]. In other words, the utility which each customer derives from the product or service is a function of its specific attributes, and can change dramatically as those attributes change.

As mentioned in Section 2, the specific features of MSS services will depend upon design decisions made by each intending operator. Such different feature-bundles are likely to appeal to different customer segments to different degrees, and thus have an impact on the market demand for each company's offering. A key task of marketing strategy and implementation in the pre-launch period is to design product features so as to achieve the company's objectives in the marketplace $[38,44,100]$. At the early stages of business planning for a new product, considerable latitude exists for each company in the choice of product and service attributes, and consequently there is considerable variability in the likely levels of possible demand for the product. In the case of GMSS, where lead times between project inception 
and commercial launch are so long - a lead time of eight or more years seems to be typical [110] — customer expectations and preferences may well change considerably through the planning period, adding to the uncertainty in any forecasting activity.

However, as mentioned earlier, forecasts of demand are needed by the company and its various stakeholders in order to plan the business. In addition, many of the issues involved are complex and inter-related [32], and can only be solved knowing the results of the others. Because this is impossible, interim solutions are typically adopted, with periodic revisions through a process of iteration, in a manner very analogous to a blackboard architecture for complex decision-making $[64,68]$. Some decisions, such as the choice of satellite orbit (which influences the nature of satellites to be manufactured) need to be made early in the design process and can only be revised with prohibitive financial costs and delays. Others, such as the type of retail outlets to be used, may be postponed until much closer to the launch date of commercial service and even revised subsequent to launch, if found necessary. In this situation, any useful demand forecasting activity must be iterative, with successive forecasts being adopted by the company as its current official forecasts.

\subsection{Primary Market Research}

The large financial stakes at risk by GMSS companies mean that the case for undertaking primary market research - in other words interviews with prospective customers $[1,26]$ — as a basis for market demand forecasts is compelling. However, primary market research in this situation is not necessarily reliable, for a number of reasons [59].

Firstly, as mentioned above, demand may depend crucially on specific service and quality features, and these are not known at the outset of the planning activity, when forecasts of demand are first needed. Indeed, one purpose of primary market research is to gather information relevant to their specification [100]. Likewise, actual demand will depend also on what alternatives, complementary and substitute services are available to customers at the time of their purchase decision. ${ }^{4}$

Secondly, even if interview respondents were to know and appreciate the exact features of a new service and of competing services, respondents are not necessarily accurate predictors of their own future behavior. Market research surveys of purchase intentions typically ask prospective customers to rate their likelihood of purchase using a qualitative linguistic scale such as: Very likely; Likely; Unsure; Unlikely; Very unlikely [44]. Even though such

\footnotetext{
${ }^{4}$ A market research technique known as conjoint analysis is often used to simulate and model such multi-attribute purchase decisions [25,100,109]. Even advice to prospective customers from others - what marketers refer to as "word-ofmouth" - can be simulated and its impact calibrated, as in [101,102].
} 
a scale permits some uncertainty about future intentions to be represented, respondents may act differently when placed in an actual purchase situation. This is especially likely to be the case with a new product category, such as GMSS, where early market research surveys have been conducted several years in advance of the service launch.

Finally, primary research is unreliable because estimating demand for a global service requires market research to be conducted across the globe. However, different cultures accord different status and meanings to a market research interview and to the questions within it [97], and statistical market research techniques do not always transfer readily across cultures (see, for example, $[11,47,95,61])$.

In addition to unreliability, another challenge for primary market research of GMSS demand is the fact of sparse target populations. Although the global market for GMS services may total thirty million or more customers by 2005 [77], the numbers of terrestrial mobile customers at this time may exceed 500 million. Indeed, one industry group recently predicted 1.7 billion terrestrial mobile customers globally by 2010 [99]. Hence, GMSS demand will be a small percentage of the total terrestrial mobile demand. If potential GMSS customers comprise, say, $2 \%$ of existing mobile users then we will need to interview an average of 50 terrestrial mobile users to locate just one potential GMSS customer. In order to make statistically-valid comparisons between potential GMSS customers (for instance, according to their country of origin or their frequency of usage) we may require a realized sample size of several hundred GMSS respondents [1,26]. To achieve 300 potential GMSS users would require interviews with 15,000 cellular customers, a sample size that would be prohibitively expensive.

As a result of the great uncertainty regarding the true levels of demand in the pre-launch situation, a situation arises which may be termed opinion proliferation. The combination of an absence of comparable historical data and the unreliability of primary market research mean there is generally no one single prevailing viewpoint regarding demand levels within an intending GMSS operator and among its stakeholders. Everyone has an opinion on the size of the market and its dynamics, and there is often no agreed or objective way to arbitrate between these opinions. Primary market research findings might conceivably provide a resolution, were they not subject to so many challenges of reliability and validity. In such circumstances, interval rather than point estimates of unknown parameters provide greater robustness, firstly because more people can typically support any selected interval than any selected point, and because they can provide an indication of the uncertainty associated with the parameter being estimated.

\subsection{The Relevance of Belief Functions}

There are several reasons for thinking that use of belief functions may be appropriate to the forecasting problems faced by intending GMSS operators. 
Firstly, because of the unresolved technological, marketing and business issues associated with planning a new high-technology business in a new market category, the situation facing the management of an intending GMSS operator as they undertake pre-launch planning is one of great uncertainty. In one typology of business uncertainty, [15], this environment would be Level 3 ("A Range of Futures") or Level 4 ("True Ambiguity") on a 4-level scale. Caselton and Luo $[10,55]$ have termed a similar situation, in the field of water resources management, decision-making under conditions of "near-ignorance". 5

Belief functions, because they permit the assignment of degrees of belief to sets of outcomes of unknown parameters without requiring further assignment to the specific point-values contained in those sets, provides a means to represent what little is known in such a situation. In our experience, telecommunications managers faced with decision-making under uncertainty, feel much more comfortable with statements such as: "I believe demand is likely to be in the range $x$ to $y$." than with statements such as: "I believe demand is likely to be exactly z." or even: "I believe demand is likely to be close to $z$ ". As Srivastava [93] has argued, belief functions provide a better framework for representation of uncertainty than does probability in such circumstances.

A second reason for believing belief functions are applicable in this situation arises from the blackboard-like process mentioned above which new telecommunications companies go through in order to resolve the many interconnected issues they face. Such a process results in a need for the company to adopt a series of forecasts, each the official company forecast until revised. These may need to be in point-form because of the nature of downstream models which use them (such as the financial forecast models, or the network sizing models) and for readiness of communication to stakeholders, such as investors and regulators. However, with any point forecast there is a danger of unjustified precision: because the forecast is expressed as a point and not an interval, stakeholders (both internal and external) can come to believe it to be more accurate than it really is. When there are so many consequences of the forecast, and so much resting on it, problems can arise with such misperceptions of accuracy, both at the time and later, for example when the forecast is revised.

Because belief functions enable degrees of belief to be assigned to intervals rather than to points, it provides the opportunity to present a point forecast as a representative point-value from an interval chosen to facilitate planning issue resolution in the current iteration. The company's beliefs about the future can be embodied in the interval, not the representative point, and this has, we believe, tremendous value. In particular, those stakeholders drawing conclusions from or making decisions on the basis of the forecasts are made aware of the degree of imprecision they embody. As is noted by Caselton and Luo [9], making decisions with weaker information is likely to lead to

\footnotetext{
${ }^{5}$ Here, just as in Caselton and Luo, this term is not used pejoratively.
} 
more equivocal views of the decision alternatives. This is particularly important for business decisions being made in a context of rapid change, where stakeholders need to keep as many options open as long as possible [15].

Finally, belief functions are relevant here because they also provide a coherent mechanism for combining disparate evidence about uncertain events. Because of the long timescales associated with implementing a GMSS business, the market environment of the intending GMSS operator has undergone significant changes in the time between project conception and launch of service. To give just one example, before 1992 most forecasts for terrestrial mobile demand for 2000 were typically under 100 million customers worldwide [41]. As mentioned earlier, a recent telecommunications industry association forecast now projects this figure to be 426 million [99]. In such a turbulent environment, evidence of future demand may be very different from different sources. Belief functions provide a means to combine these coherently.

Now, to some extent these needs could be met by a number of different formalisms, including interval [8] and fuzzy [114] probability models. Even if the decision is taken to adopt a belief function approach the question remains as to which of the three variations on the belief function theme, mentioned in Section 1 , should be adopted. When faced with this choice, we chose to use the transferable belief model. We did this partly because we find it the most intuitively appealing variant, partly because of the solid foundations provided by Smets' axiomisation of credal level beliefs [85], and partly because of the separation it maintains between the credal level, which is what we are mainly dealing with here, and the pignistic level [89].

In Section 5, we build a model using the TBM, and demonstrate how it may be used to incorporate evidence obtained from the entry of the first operator into the market into forecast models developed for a later entrant.

\section{GMSS Forecasting Model Structure}

In this section, we outline the structure of a forecasting model for estimating demand for GMSS. The model approach adopted is a hierarchical one, centered on end-user application segments, and is a typical market forecasting model in new telecommunications ventures. We begin by dividing the total global market into distinct geographic territories (such as countries) and then, within each territory, we divide demand into three components, according to the different application segments for GMSS described in Section 2 above: Mobile Enhancement; Fixed Extension; and Niche Applications. Total global demand is obtained by summing demand in all distinct geographic territories. Total demand in a specific territory is obtained by summing demand across these three application segments in that territory, and so we assume here that demand for each can be calculated separately. ${ }^{6}$

\footnotetext{
${ }^{6}$ Note that we are here assuming that demand in one segment is independent of that in another, which will not be true in reality. For example, customers living
} 
We now describe the forecasting model structure for just the Mobile Enhancement component. Demand in this segment will arise both from people who are existing customers terrestrial mobile network and those who are not. We assume the latter all live outside terrestrial mobile coverage areas, as those inside who desire GMSS but are not at that time customers of terrestrial mobile networks can be directed to become terrestrial mobile customers in order to obtain GMSS services. ${ }^{7}$

Of all those people who are customers of terrestrial mobile networks, we assume some percentage, say $\theta$, will become customers of a GMSS network by, say, the end of the year 2008. This date is selected because it is ten years after the launch of the first GMSS operator, Iridium; for the purposes of forecast modelling, the total number of customers by this time can represent the long-run potential of the GMSS market, called the market saturation level. We refer to $\theta$ as the longrun market penetration level for demand for Mobile Enhancement GMS Services. ${ }^{8}$

Our next step is to forecast the market demand for each year within this ten-year period. ${ }^{9}$ The yearly forecasts, expressed as percentages of the total number of terrestrial mobile customers, begin at zero and rise to the market saturation level $\theta$ over the course of the ten-year period. Uptake of new products or services in this way is typically modeled by marketers with an S-shaped diffusion curve $[2,4,22,54,56,62]$, this is a curve which grows slowly at the beginning, accelerates quickly through some middle period, and then flattens off to an asymptotic point toward the end of the period of forecasting, as market saturation is reached. As well as having been validated empirically [78], such diffusion models are appropriate because they potentially reflect, for instance, the following: the differential growth through time in sales and distribution capabilities of companies serving a target market; the differential growth through time in the awareness and education of prospective customers

outside fixed and mobile network coverage may opt for either or both of Mobile Enhancement and Fixed Extension services. This particular example reflects a potential distribution channel conflict, which would require a marketing strategy decision to resolve.

7 Again, the appropriate treatment of this anomaly in the forecasting model will ultimately depend upon marketing strategy decisions taken by the company using the model.

${ }^{8}$ In reality, demand will most likely depend heavily on pricing structures and levels. However, price will be one feature among many in the bundle of attributes upon which prospective customers make their purchase decisions. At the early stages of new GMSS business planning, price levels - like most everything else in the decision mix of the operator-are very uncertain. We therefore ignore price as an issue, in the same way we are ignoring attributes such as distribution reach, both of which are typical approaches at the outset of market modeling.

${ }^{9}$ In practice, certain stakeholders, such as financial and security industry regulators, often require more granular forecasts, especially for the early years of commercial operation. 
about the products or services in the market category; the entry of new suppliers to the market category; and the product life cycles to which marketers believe all products and services are subject $[53,63,100]$.

Forecasting the uptake of GMSS services in our hierarchical model is thus equivalent to distributing the percentage $\theta$ across the ten year forecasting period according to some $\mathrm{S}$-curve model. One can use primary market research to forecast demand across years in this manner, although this is not commonly done because long-run purchase intentions are likely to be even less reliable than are short-run intentions. Alternatively, assuming the same dynamics exist in this market as in some other market (although possibly from a different base level) allows us to use an historical diffusion curve, such as in this case that for the growth in penetration of terrestrial cellular services, as a benchmark. This results in a yearly-forecast of GMSS demand for the entire market - that is, a forecast for the demand that will be experienced by all operators combined.

Any one GMSS operator will also need to know its own forecast subscriber numbers, for example, for network sizing and financial modelling. Such market shares can be calibrated by means of primary market research using a conjoint model once information on the likely feature-attribute sets of the various competitors in the marketplace is known. Before such primary information is available, appropriate assumptions about the distribution of market share between the respective operators can be made. In the description of the model presented here, we assume only the three global voice operators mentioned in Section 2, although in reality the existence of regional MSS competitors and data-only GMSS competitors should be incorporated into the model.

We therefore have an hierarchical forecasting model for the Mobile Enhancement segment in any territory which begins with the total number of terrestrial mobile customers in a specific territory and results in forecast GMSS demand for each operator for each year to 2008. In the way this model has been constructed, the parameter $\theta$ can vary by territory, which is likely to be the case once GMSS services are launched. Allowing the parameter to vary by territory also provides the means to forecast overall demand when service is not offered in particular territories, either due to failure to achieve necessary regulatory permissions or for reasons of business strategy: in such cases the parameter can be set to zero in the model. However, in the initial period of forecasting, when ignorance is greatest, there is likely to be insufficient information on which to assign differential values to $\theta$ in different territories. At such times, a constant value, across all territories can be assumed or estimated. For simplicity, this is the approach adopted here. Likewise, benchmark uptake data and market shares may also be varied by territory.

The other two application segments can be treated in a similar fashion, with, of course, appropriate modifications, for example, to the historical 
benchmark data used for estimating uptake. In the case of the Fixed Extension segment, for instance, the penetration of residential satellite television or microwave ovens may be a more appropriate benchmark than mobile telephones. The niche application segment would need to be further sub-divided into the different types of applications, such as: marine applications; aeronautical applications; land transport applications; etc. Further subdivision is appropriate here, as each of these sub-segments contains a variety of different user types and segments.

The authors are familiar with the forecasting model structures used by two intending satellite network operators, and they are very complex. Complexity arises because of the variety of services being planned for offer to customers, the diversity of target customer segments, their likely needs and patterns of usage, and the complex, global nature of the GMSS business. ${ }^{10}$ Although the model presented here is a simplification of the actual model structures adopted by these MSS operators, it is sufficiently realistic to represent the main features of the application domain, and to demonstrate the applicability of the TBM.

\section{Applying the Transferable Belief Model}

In this section, we present an example of the TBM applied to the forecasting model described above. In order to do this, we begin by assuming that forecasting is initially being undertaken before any of the three operators has launched commercial services, that is before November 1998, when Iridium began offering public services. Moreover, in forecasting GMSS demand, we do so from the perspective of a late entrant to the market (i.e. not Iridium). Publicly-available information about Iridium's launch will then be used to revise the forecast, using Dempster's rule of combination.

\subsection{Preliminaries}

Until Iridium's commercial launch of service, none of the three intending operators knew if either of the other two would enter the market. Now that Iridium has launched, none of the three operators knows if one or both the

\footnotetext{
${ }^{10}$ For example, it is common in terrestrial mobile and fixed telecommunications networks to assume an average usage per customer, often measured as Minutes Of Use (MOU) per month [38]. In these networks, the MOU measure is often disaggregated by customer segment or by hour of the week, so as to estimate peak network utilizations $[52,113]$. With GMSS, customers with mobile terminals may travel anywhere across the globe and make and receive calls wherever they are. In order, then, to accurately estimate network utilization at any time requires aggregating usage by customers from one country currently in a second country calling or receiving calls from someone in a third country, across all time periods and all possible combinations of countries.
} 
two late entrants will succeed in achieving commercial launch. In other words, none of the three GMSS operators knows if 1, 2 or 3 operators will enter the market, and, of course, none knows if all those who enter the market will survive in the long term. ${ }^{11}$ Because the principles are identical for each application segment, our example is confined to the Mobile Enhancement segment. In this section, therefore, mention of demand, market, capacity, and so on refers only to the Mobile Enhancement segment.

For any given level of demand, we assume the number of operators offering GMSS services has an impact on the profitability of those in the market: it is better for the operators concerned to divide a given market size by one or two than by three [3]. For simplicity of modelling, we also assume that the saturation level of demand is not affected by the number of operators, although economic theory would suggest that more competitors would lead to lower prices which would in turn lead to greater demand $[3,46] \cdot{ }^{12}$ In the early days of business planning, when commercial launch is still some years away, no operator has any information on the likely market shares they will each achieve once all are in the market. In these circumstances, it is usual to assume equal shares, possibly modified to give an advantage in the early years to the early market entrants. We will assume equal shares in this example, noting that when the service features of each intending operator are better understood, it is possible, as was mentioned earlier, to undertake market research using conjoint analysis to better calibrate market shares. Thus our analysis here can be considered as a first attempt at prediction, an attempt which would later be refined.

In addition to assuming that all operators have equal market share, we assume that each operator has the same, fixed level of network capacity, as measured by numbers of customers. This is not true in reality because of the different system designs adopted by each and the possibly very different usage profiles of the customers each operator will attract. However, since no operator knows the capacity of its competitors, assuming a constant capacity is a reasonable first approximation prior to launch of service. For the purposes of this example, we assume that each operator has total capacity of 2 million customers. ${ }^{13}$

${ }^{11}$ As an example of the kind of event that can affect market entry, Globalstar's plans received a major setback in September 1998 with the explosion soon after launch of the rocket carrying its first 12 satellites, which resulted in their failure to achieve their designated orbiting positions [21,77]. The fact that the construction of a GMSS network is a long and risky process means that right up until the launch date there is considerable uncertainty about whether or not a company will survive long enough to see any revenue.

12 The impact of additional competitors is often approximated in forecasting models in practice by assuming a faster uptake rather than a higher saturation level.

${ }^{13}$ In fact, GMSS operators may have difficulty in arriving at a single figure for their own network capacities, because of the non-uniform nature of the frequencies they have generally been assigned in different countries around the world, and the fact 
Likewise, assume each operator has a level of demand at which the business breaks-even. ${ }^{14}$ Again this is likely to differ - and markedly — for the three companies in question, but no operator knows the true level for the other two, and, in the early stages of planning, is likely to have only a very uncertain view of its own breakeven point and the associated financial sensitivities. Hence, we again assume each has the same break-even level, and, for the purposes of this example, that this common level is 1 million customers. Thus, if total market demand was under 3 million customers and all three operators enter the market, none would break even. ${ }^{15}$ If only two operators enter the market, the market need only be 2 million in total for break-even to be achieved.

These considerations have defined two threshold values in the level of demand - the two break-even points of 2 million and 3 million total customers - which have major consequences for the investors in the GMSS operators undertaking the forecasting. We will now use these and similar considerations at the other end of the forecast spectrum to construct a set of intervals for the level of demand. These intervals will be defined in terms of their decision consequences to the operator undertaking the forecasting.

Recall that in Section 3 we mentioned that GMSS satellite networks will last between 5-10 years before needing to be replaced. Replacement of the initial networks by so-called second-generation satellite networks will enable each operator to take advantage of advances in satellite and launch technology, and in telecommunications generally, as well as providing new services not capable with the first generation of satellites. Accordingly, operators will need to expend time and effort on designing and implementing their second generation networks, and may even need to commit to proceeding with them before the initial commercial launch of service, due to the long-lead times involved in satellite manufacture and launch [110].

In this regard, the more positive is the market forecast, the greater is the argument for advancing development of the second generation. If market demand exceeds the total capacities of all operators, then it goes unmet. ${ }^{16}$ The excess is revenue, and hence profit, which no one (under the assumptions of equal shares and capacities) obtains. ${ }^{17}$ Therefore, if demand were believed

that because low-earth and medium-earth orbit satellites are moving relative to a fixed point on the earth, the extent of network availability to a customer at any such point will be different at different times, even without network congestion.

${ }^{14}$ Break-even is the point at which all costs - which may include both interest on borrowed funds and taxes due-are covered, but there is no profit. According to press reports, Iridium requires 500,000 customers to reach this point [24].

15 Recall that we are assuming equal market shares.

${ }^{16}$ Globalstar reportedly estimates the total potential MSS market demand at 30 million customers and is aiming for $10 \%$ of this by 2002 [77] They believe the three companies combined would serve only $50 \%$ of the total demand.

17 Because telecommunications services are perishable resources-unsold network minutes at any one time cannot be offered for sale at a later time-it behooves 
by an operator to be likely to exceed, say, 1.5 times capacity levels, then a good case could be made to advance the deployment of the second generation system. If demand were believed to exceed total capacity by, say, three times, then, one could argue, such demand levels would be likely to attract additional entrants, and a case could be made for a first-generation system with significantly greater capacity than currently envisaged. As the reader probably understands, these decisions have associated with them significant financial consequences and risks.

Putting these considerations together, we can therefore envisage five intervals for the forecast for saturation demand. In ascending order of number of customers, these are:

1. Market demand believed to be less than 2 million customers, at which point two operators each break even. In this case, the operator undertaking the forecasts would not proceed with entry to the market.

2. Market demand believed to be between 2 and 3 million customers, at which point three operators each break even. In this case, the operator undertaking the forecasts would again not proceed with entry to the market if it was believed that all three operators would enter the market.

3. Market demand believed to be between 3 million and 9 million customers $(1.5 \times 3 \times 2)$ : continue with current plans for first-generation system and do nothing about second-generation system.

4. Market demand believed to be between 9 million and 18 million customers $(3 \times 2 \times 3)$ : advance plans for second-generation system.

5. Market demand believed to be above 18 million customers $(3 \times 2 \times 3)$ : plan for enhanced first-generation system.

It is important to realize that, from the perspective of the corporate management involved, these intervals are not arbitrary. As the description given for the way in which they were derived indicates, each interval represents different sets of consequences for the company and different sets of feasible strategic options. Of course it is possible to derive different intervals based on different sets of assumptions about the number of customers required for an operator to break even and so, but the point is that it is possible to come up with meaningful intervals of which these are a suitable example.

It is also important to realize that the use of the transferable belief model is not restricted to problems in which the frame of discernment is divided into a finite set of non-overlapping intervals like those given here. See [84] for details on how to handle cases where the value of $\theta$ ranges over any subset of the $[0,1]$ interval. Here the point is that the transferable belief model is capable to handling whatever set of intervals are decided upon.

the operators to adopt so-called yield management techniques [106], which seek to optimize profits by judicious design and adoption of feature bundles targeted at different customer segments. 


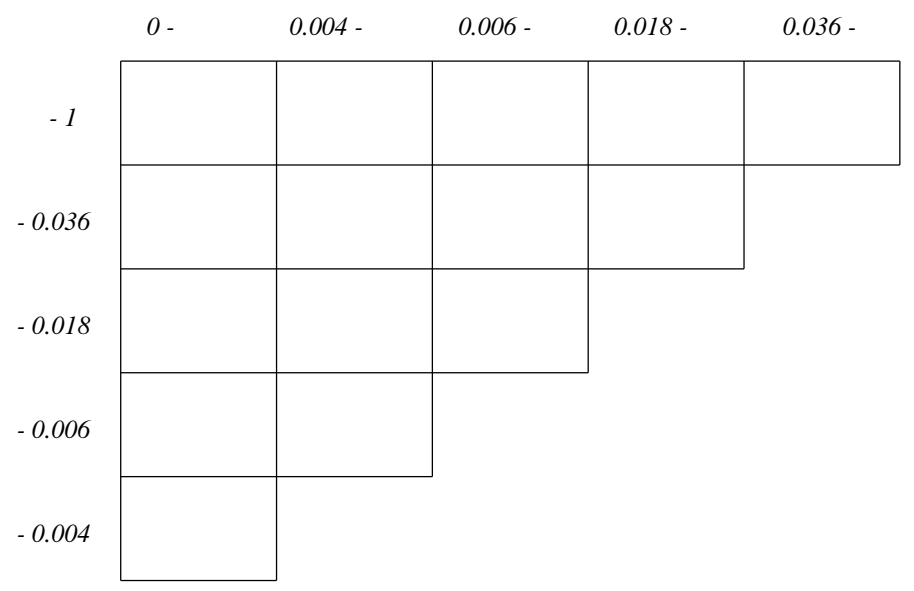

Fig. 1. The frame of possible subsets for parameter $\theta$. The labels along the top of the cells are the lower bounds on $\theta$, and those down the left hand side are the upper bounds. The range of values indicated by a given cell is the combination of its lower column bound and its upper row bound. Thus the top left hand cell corresponds to $0 \leq \theta \leq 1$, and the cell in the second column of the third row corresponds to $0.004 \leq \theta \leq 0.018$

We are here assuming that GMSS demand consists only of the one application segment: Mobile Enhancement. If we assume that there will be 500 million terrestrial cellular customers worldwide in 2008, then the customer ranges listed here can be converted to intervals for $\theta$, the saturation proportion of terrestrial mobile customers who are also GMSS customers: ${ }^{18}$

$$
\begin{aligned}
0 & \leq \theta<0.004 \\
0.004 & \leq \theta<0.006 \\
0.006 & \leq \theta<0.018 \\
0.018 & \leq \theta<0.036 \\
0.036 & \leq \theta \leq 1
\end{aligned}
$$

We next examine basic belief assignments (BBAs) across the possible unions of these five sets. As with the applications discussed by Caselton and Luo $[9,55]$, only unions of contiguous sets have meaning in the market demand context, and so we are able to represent the frame of possible subsets in a two-dimensional diagram, as shown in Figure 1. For ease of labelling, the cells in this figure are represented as the intersections of the events denoted by the respective column and row labels. Thus, the cell which is third from the left in the second row is the event $\{0.006 \leq \theta<0.036\}$, which is formed from the intersection of the event denoted by the column label $\{0.006 \leq \theta\}$ and that

\footnotetext{
${ }_{18}$ Such a division of the universe of discourse into meaningful intervals could also form the basis for semi-qualitative order-of-magnitude reasoning using interval algebras [65], regarding possible competitor strategies and counter-strategies.
} 


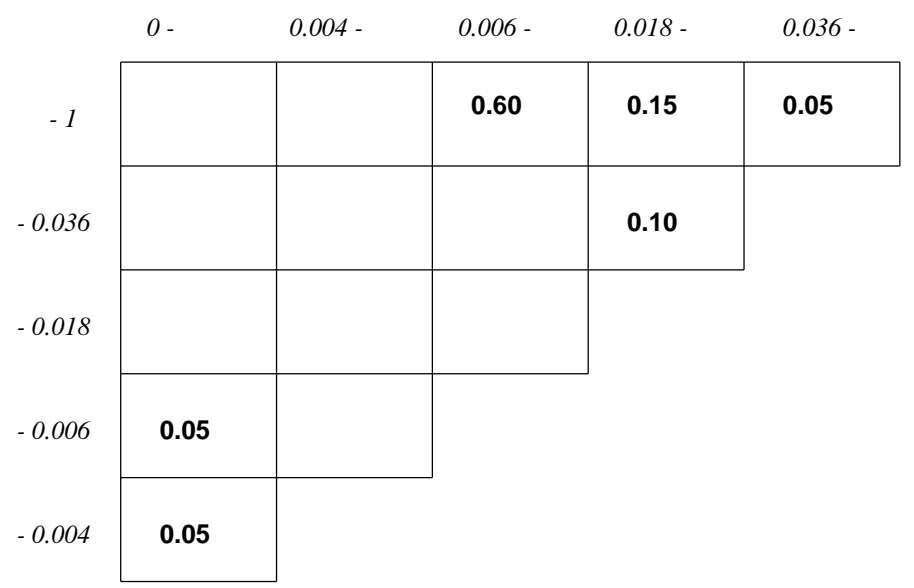

Fig. 2. BBA1: Initial Subjective Judgment. The labels along the top of the cells are the lower bounds on $\theta$, and those down the left hand side are the upper bounds. The range of values indicated by a given cell is the combination of its lower column bound and its upper row bound. Thus the top left hand cell corresponds to $0 \leq \theta \leq 1$, and the cell in the second column of the third row corresponds to $0.004 \leq \theta \leq 0.018$.

denoted by the row label $\{\theta<0.036\}$. The respective row and column labels therefore give the end-points of the interval represented by that particular cell.

\subsection{Initial Subjective Judgment}

We begin by assigning basic belief masses to the 15 events represented by the diagram. One can imagine these being assigned as a result of discussions with the internal company managers involved. ${ }^{19}$ In our experience, most people readily understand the idea of allocating a fixed total quantity of belief to different propositions, and consensus ageement among managers of the one company is also quite feasible. It is important to note that this assignment may be subjective, arising from discussions and compromise between different people with different perspectives and interests. We let the function $m_{1}(\cdot)$ denote this first Basic Belief Assignment (BBA).

- Of the total belief, $5 \%$ is assigned to the proposition that the market is too small for 3 players, i.e. $m_{1}(0 \leq \theta<0.006)=0.05$.

- Of the total belief, $5 \%$ is assigned to the proposition that the market is too small even for 2 players, i.e. $m_{1}(0 \leq \theta<0.004)=0.05$.

- Of the total belief, $15 \%$ is assigned to the proposition that the market is bigger than we are currently planning for, i.e. $m_{1}(0.018 \leq \theta)=0.15$.

19 The assessment of basic mass assignments is discussed by Smets and Kennes $[86,89]$. 
- Of the total belief, $10 \%$ is assigned to the proposition that we will need to advance the development of the second generation, i.e. $m_{1}(0.018 \leq \theta<$ $0.036)=0.10$.

- Of the total belief, $5 \%$ is assigned to the proposition that we will need to redesign the first generation system, i.e. $m_{1}(0.036 \leq \theta)=0.05$.

- Of the total belief, $60 \%$ is assigned to the proposition that the market is large enough for all three players, i.e. $m_{1}(0.006 \leq \theta)=0.60$.

- The belief allocated to all other subsets of the frame is zero.

Figure 2 shows this BBA, which we call BBA1, diagrammatically. Note that elicitation of such beliefs does not require managers to make explicit their assumptions as to causal influences on the outcomes, nor the relationships between such influences, which would be required, for example, to undertake Structured Scenario Analysis [27]. Belief functions are thus more appropriate in this uncertain domain.

\subsection{Market Research Results}

We assume next that a second BBA arises from the collection of primary market research data, subsequently to the initial subjective estimation of BBA1. This may take the form of a global market research survey of current terrestrial cellular users who are prospective customers of MSS services. If an MSS service with broadly-defined features, functionality and price is described to respondents and they are asked what is the likelihood that they would purchase such a service at any time in the future, the following responses could be obtained (with the percentage figure being the proportion of respondents agreeing with the verbal description of their likelihood of purchase):

$\begin{array}{lr}\text { Very Likely: } & 2 \% \\ \text { Likely: } & 5 \% \\ \text { Unsure: } & 20 \% \\ \text { Unlikely: } & 45 \% \\ \text { Very Unlikely: } & 28 \%\end{array}$

To produce a single forecast of uptake, it is common in market research to weight these percentages and then sum them. In doing so, the weights correspond to the proportion of respondents who are believed to be going to act according to their stated intentions in the reference time period. It is assumed that between $50 \%$ and $100 \%$ of the respondents answering "Very Likely" will purchase at some time in the future; that between $30 \%$ and $70 \%$ of the respondents answering "Likely" will purchase; and that none of the respondents answering "Unsure", "Unlikely" or "Very Unlikely" will purchase. Applying these weights results in the estimated penetration level varying between 0.025 and 0.055 . Thus the primary market research has provided evidence for a saturation penetration parameter value of $\theta \geq 0.018$, 


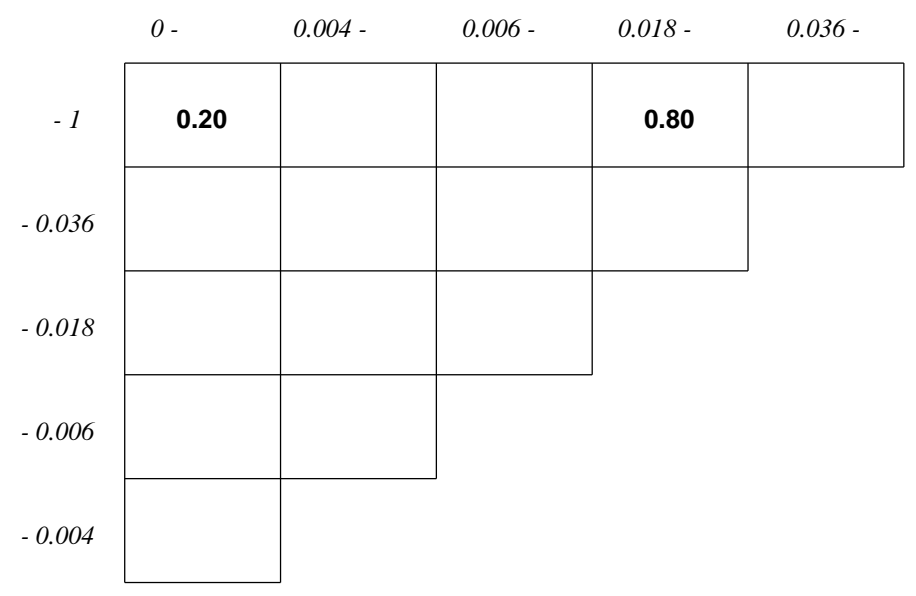

Fig. 3. BBA2: Market Research Results. The labels along the top of the cells are the lower bounds on $\theta$, and those down the left hand side are the upper bounds. The range of values indicated by a given cell is the combination of its lower column bound and its upper row bound. Thus the top left hand cell corresponds to $0 \leq \theta \leq 1$, and the cell in the second column of the third row corresponds to $0.004 \leq \theta \leq 0.018$.

as this is the subset of the frame frame of discernment which includes the interval suggested by the market research.

However, for the reasons outlined in Section 3 above, it is assumed that we are not fully confident in the reliability of the market research results. Accordingly, we can imagine that the market research agency undertaking the project is asked to provide their belief, based on their long experience of primary data gathering, that the true parameter is within the interval indicated by the research. Suppose that their subjective belief (independent of the subjective estimates of the GMSS company managers used for BBA1) is allocated in the proportions of $80 \%$ to the proposition that the research is correct, and $20 \%$ to the proposition that the true value of $\theta$ is anywhere between zero and one. In other words, if we denote this second BBA by the function $m_{2}$, then we have the following values:

- $m_{2}(0.018 \leq \theta \leq 1)=0.80$

- $m_{2}(0 \leq \theta \leq 1)=0.20$

The resulting BBA, called BBA2, is shown in Figure 3. For very many purposes, a point estimate of demand is required, not a range. Commonly, specific weights are assumed for the proportions of intenders who eventually purchase, for instance $80 \%$ of those responding "Very Likely" and $50 \%$ of those responding "Likely", which would yield an estimate for $\theta$ of 0.041 . This value is in fact close to the mid-point, 0.040 , of the range identified by the market research. 


\subsection{First Combination}

We have now two independent assignments of belief to the frame. These can be combined using the normalised version of Dempster's rule of combination, with the resulting BBA denoted by the function $m_{3}$, as follows:

$$
m_{3}(C)=\frac{1}{1-k} \sum_{A \cap B=C} m_{1}(A) \cdot m_{2}(B)
$$

where

$$
k=\sum_{A \cap B=\emptyset} m_{1}(A) \cdot m_{2}(B) .
$$

The resulting BBA (called BBA3) is shown in Figure 4. As an example, we calculate $m_{3}(0 \leq \theta<0.004)$. Considering only non-zero values, the numerator of the combination formula is equal to:

$$
\begin{aligned}
m_{3}(0 \leq \theta<0.004) & =m_{1}(0 \leq \theta<0.004) . m_{2}(0 \leq \theta \leq 1) \\
& =0.05 \times 0.20 \\
& =0.01
\end{aligned}
$$

Calculation shows that the normalizing constant $k=0.08$, and so applying the combination formula gives:

$$
\begin{aligned}
m_{3}(0 \leq \theta<0.004) & =1.087 \times 0.01 \\
& =0.011
\end{aligned}
$$

to three decimal places. The use of the normalized version of Dempster's rule implies the adoption of the closed world assumption about the frame of discernment. In our particular case, this is natural since it is logically impossible for $\theta$ to take a value outside the range $0 \leq \theta \leq 1$.

The calculation can be interpreted as follows. The market research provided strong evidence that $\theta$ was above 0.018 , and as a result the balance of the belief assignment moves from the interval $[0.006,1.0]$ to the interval $[0.018,1.0]$. However, there are still beliefs assigned to values of $\theta$ outside this range - a total of $15.2 \%$ is so assigned. The use of a single estimate or the most likely range as a result of the market research may create a false impression of precision. The use of belief functions here has ensured we have not overlooked the uncertainty inherent in the estimates. In addition, for simplicity of presentation of this example, we only update the forecast once here with market research findings. However, with a project of the timescales of GMSS ventures, market research is undertaken repeatedly and forecasts will be updated accordingly. This can, of course, be captured in the belief function model by repeated combinations.

It should also be noted that we are only operating at the credal level at this point. Indeed, we are only dealing with mass assignments and their 


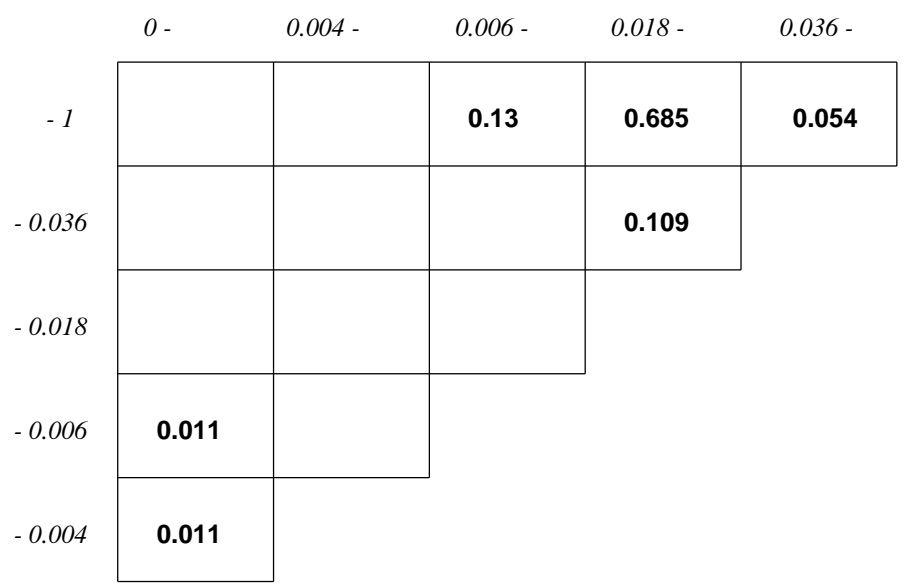

Fig. 4. BBA3: Combination of Subjective Judgment with Market Research. The labels along the top of the cells are the lower bounds on $\theta$, and those down the left hand side are the upper bounds. The range of values indicated by a given cell is the combination of its lower column bound and its upper row bound. Thus the top left hand cell corresponds to $0 \leq \theta \leq 1$, and the cell in the second column of the third row corresponds to $0.004 \leq \theta \leq 0.018$.

combinations. We can, of course, use these mass assignments to calculate beliefs. In particular, we can calculate the belief that $\theta$ takes a value between 0 and 0.006 . The general formula for establishing belief in a subset of the frame of discernment, $A$, is:

$$
\operatorname{Bel}(A)=\sum_{B \subseteq A} m_{3}(B)
$$

which gives us, for instance:

$$
\begin{aligned}
\operatorname{Bel}(0 \leq \theta \leq 0.006) & =m_{3}(0 \leq \theta \leq 0.004)+m_{3}(0 \leq \theta \leq 0.006) \\
& =0.011+0.011 \\
& =0.22
\end{aligned}
$$

If we want to use these beliefs to make a decision about what to do, and we want to employ decision analysis [76] to do this, we need to convert the masses into probabilities. This can be done using Smets' pignistic transformation [89], which gives:

$$
\operatorname{Pr}(B)=\sum_{A} m(A) \frac{|B \cap A|}{|A|}
$$

Essentially this takes the mass assigned to a set $A$ and distributes this equally over all the members of $A$. Note that because our underlying sets $A, B$, etc are real intervals and not finite sets, we interpret the weighting fraction which is 


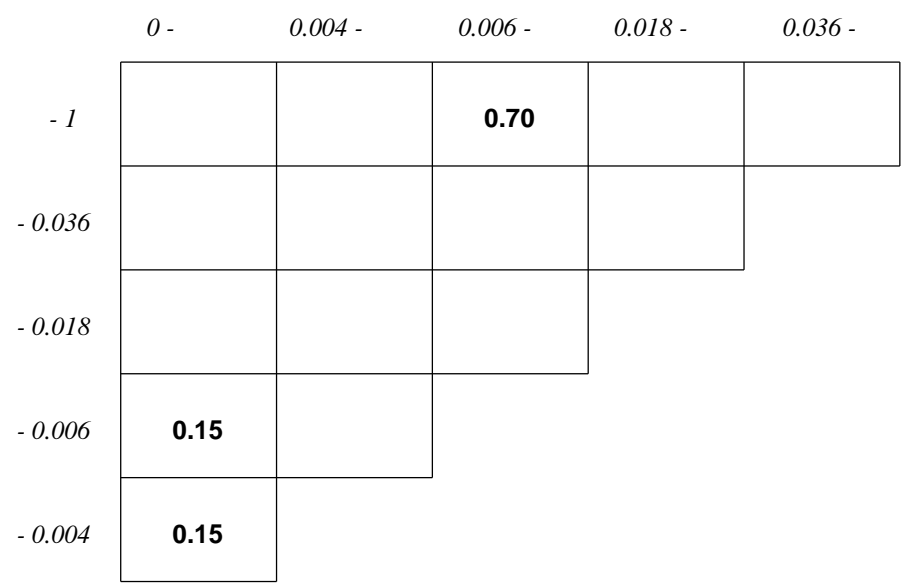

Fig. 5. BBA4O: Optimistic Analysis of Iridium Experience. The labels along the top of the cells are the lower bounds on $\theta$, and those down the left hand side are the upper bounds. The range of values indicated by a given cell is the combination of its lower column bound and its upper row bound. Thus the top left hand cell corresponds to $0 \leq \theta \leq 1$, and the cell in the second column of the third row corresponds to $0.004 \leq \bar{\theta} \leq 0.018$.

multiplied by each $m(A)$ as the ratio of the lengths of the respective intervals, $B \cap A$ and $A$. The result is the pignistic probability for $B$, the probability which should be used when making decisions as opposed to the belief mass which should be used when reasoning about beliefs. In our example, for instance, we can calculate the pignistic probability of $(0.036 \leq \theta \leq 1)$ as:

$$
\begin{aligned}
\operatorname{Pr}(B) & =\frac{0.054}{1}+0.685 \frac{1-0.036}{1-0.018}+0.13 \frac{1-0.036}{1-0.006} \\
& =0.853
\end{aligned}
$$

Similar calculations can be carried out for other possible values of $\theta$.

\subsection{Iridium Launch}

As mentioned, Iridium launched their commercial service, the world's first public Global Mobile Satellite Service, in the last quarter of 1998. The launch was originally scheduled for 23 September 1998 [34] and then postponed to 1 November due to technical problems [35]. By 31 May 1999, the company reportedly had signed up just 10,300 customers compared with the 27,000 they were aiming for by this date [110], and the target of 500,000 to 600,000 customers by the end of 1999 [36]. By August 1999, they had an estimated 20,000 customers [13].

This failure is dramatic, and resulted in the departure in the first few months of 1999 of the company's Chief Executive Officer, its Chief Financial Officer and its head of Marketing [31,75]. The company's key sponsor, 
Motorola, warned in official filings in May 1999 that Iridium may have to declare bankruptcy [24], and in August, the company filed for so-called Chapter 11 protection from its creditors as part of bankruptcy proceedings $[13] .{ }^{20} \mathrm{~A}$ number of reasons have been publicly proposed for this lack of marketplace success, including: technical performance problems [75,110]; the mis-timing of pre-launch marketing communications and advertising campaigns [31]; slow production and distribution of user terminals [37]; poor sales efforts by the company's distribution partners $[14,31,37,110]$; difficulties with training sales staff [37]; difficulties in responding to sales leads and reaching potential customers $[14,36]$; and the company's "complex and expensive call pricing plan" $[14,110]$.

These possible causes for failure to achieve sales targets are primarily ones of execution, especially marketing and commercial execution. ${ }^{21}$ In other words, Iridium's failure to achieve its sales targets is not, in itself, necessarily evidence that market demand for MSS is smaller than anticipated. Accordingly, opinions may vary as to whether Iridium's apparent market failure is due primarily to poor marketing and sales execution or due to there being insufficient demand for GMSS. Both views have been proposed in the published accounts of Iridium's progression toward bankruptcy [14]. Recall that we are undertaking this forecasting exercise from the perspective of a potential competitor to Iridium. In order to ensure distinctness of belief assignments and to ensure that internal biases (i.e. internal to the company doing the forecasting) do not color the mass assignment, one could imagine seeking the opinions of external GMSS experts as to the true market size in the light of Iridium's post-launch experiences. If undertaken in a systematic way, such a sounding of outside experts (for example, trade journalists, investment analysts, regulators, etc) is known as a Delphi study [40], and is a common market research technique $[58,60,99]$. For this work we suppose that a Delphi study is undertaken, and that the opinions of the experts polled regarding the size of the GMSS market coalesce around two views. These views depend upon which attribution for Iridium's apparent failure is most strongly believed by the experts.

Those experts believing the cause of Iridium's problems lie with the company itself remain optimistic about the size of the GMSS market, although they do assign a non-zero belief mass to the events that the market is too small for viability. This mass assignment is shown in Figure 5 (BBA4O). On the other hand, those experts who believe that Iridium's apparent failure is due to the size of the GMSS market being much smaller in reality than fore-

${ }^{20}$ Two weeks after Iridium's filing, ICO also sought Chapter 11 protection from its creditors. ICO had failed to raise the additional cash needed to execute its original plans, a failure caused in part by investor nervousness following Iridium's marketplace failure [12].

21 They are in fact not uncommon with the launch of new mobile telecommunications services $[29,38]$. 


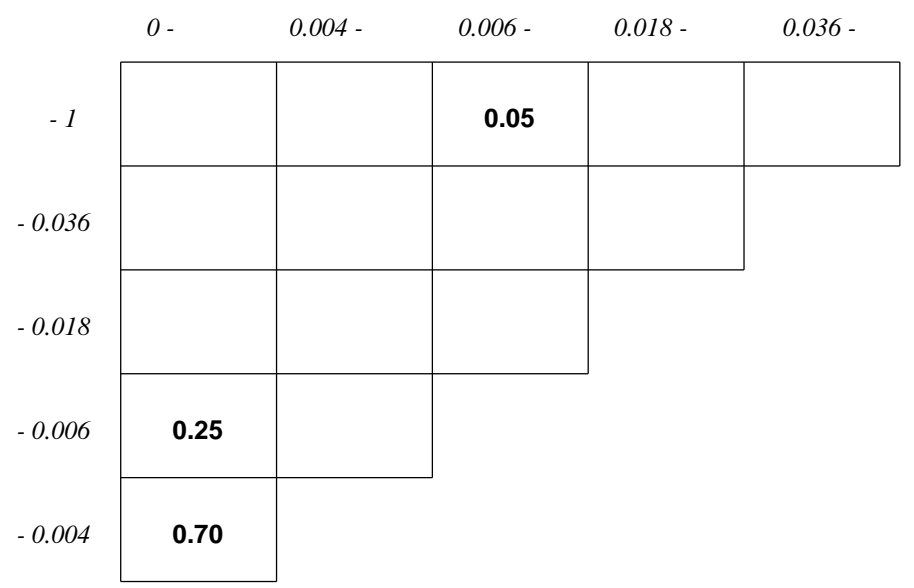

Fig. 6. BBA4P: Pessimistic Analysis of Iridium Experience. The labels along the top of the cells are the lower bounds on $\theta$, and those down the left hand side are the upper bounds. The range of values indicated by a given cell is the combination of its lower column bound and its upper row bound. Thus the top left hand cell corresponds to $0 \leq \theta \leq 1$, and the cell in the second column of the third row corresponds to $0.0 \overline{04} \leq \bar{\theta} \leq 0.018$.

cast assign far greater belief mass to the events that the market is too small for viability, as shown in Figure 6 (BBA4P).

\subsection{Second Combinations}

Similarly to the first combination, we then combine the previous combined belief assignment, BBA3, with the both the optimistic and the pessimistic expert opinions of the market size following Iridium's launch, BBA4O and BBA4P. The resulting second combinations, BBA5O and BBA5P, are shown in Figures 7 and 8, respectively.

In the optimistic scenario, the balance of belief mass following the Iridium launch is again on $\theta$ being above 0.006 , and so the weight of the combined BBA is to the right-hand end of the diagram. In this case, just under $1 \%$ of the the mass is assigned to the proposition that the market size is insufficient for viability for 2 or 3 operators. In the pessimistic scenario, by contrast, greater mass is assigned to the opposite end of the diagram, with almost $30 \%$ being assigned to the proposition of non-viability.

Which of these two scenarios is believed will depend upon the opinions of the management of the company undertaking the forecasting, and upon the specific purposes for which the forecasting activity is being undertaken. Depending on such purposes, either an optimistic or a pessimistic forecast may be appropriate. Indeed, both may be appropriate simultaneously, for example when best-case vs. worst-case planning is being undertaken. If a single mass assignment were to be required which incorporated both the optimistic and 


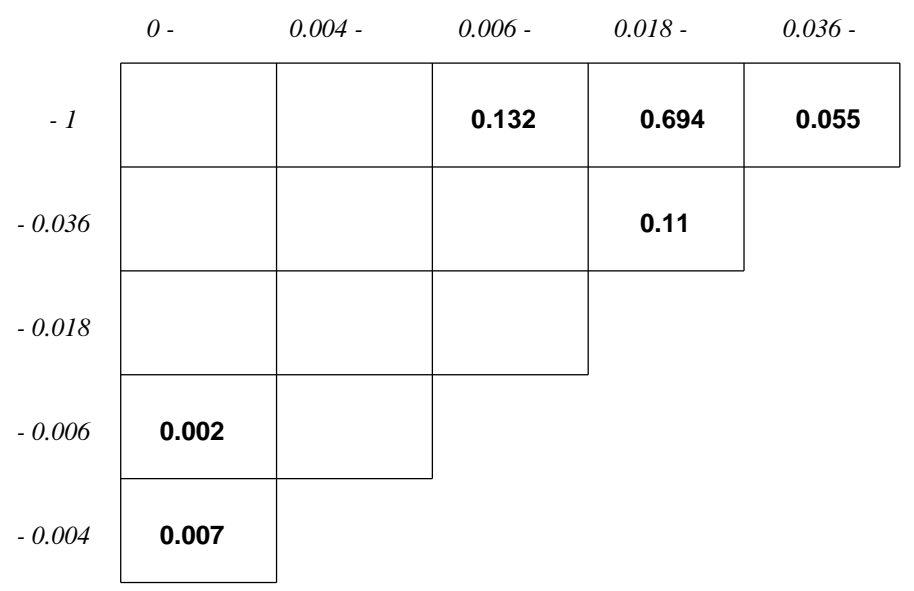

Fig. 7. BBA5O: Optimistic Second Combination. The labels along the top of the cells are the lower bounds on $\theta$, and those down the left hand side are the upper bounds. The range of values indicated by a given cell is the combination of its lower column bound and its upper row bound. Thus the top left hand cell corresponds to $0 \leq \theta \leq 1$, and the cell in the second column of the third row corresponds to $0.004 \leq \theta \leq 0.018$.

the pessimistic views of GMSS market demand, then Dempster's rule of combination could be used again with BBA5O and BBA5P, possibly weighted by the relative proportions of Delphi experts supporting the two scenarios.

\subsection{Refinements of the model}

The model developed in previous sections is, from the perspective of the TBM itself, quite a simple model. That is not to say that such a model is not useful for demand forecasting, but it does mean that the theory can be used to build much richer models. Two such refinements are particularly worth considering.

The first refinement, which was hinted at above, is that of weighting the various pieces of evidence. The model we presented took the expert opinion and market research results at face value - if market research indicated that there was a $5 \%$ chance that the market is too small for three players, the fact "market is too small for 3 players" was given a mass of $5 \%$. It is easy to develop models in which these opinions are weighted, so that, for instance, it is possible to represent the fact that we, the model builders, only believe that the market research results have a $75 \%$ chance of being correct. Indeed, it is possible to build models which not only take such information into account, but also update these weights based on the degree to which past information agreed with what actually happened. Such a model, in a rather different context, is discussed in [69]. 


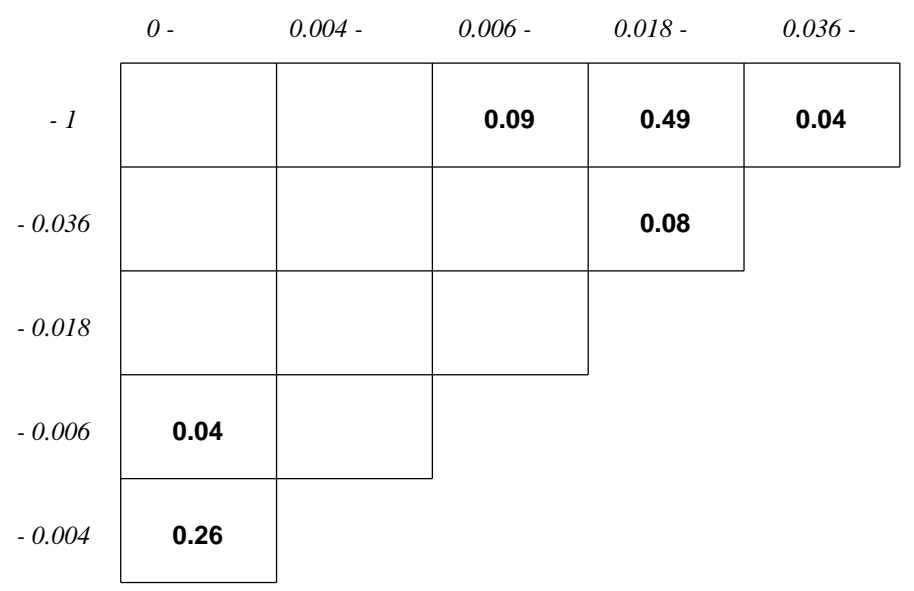

Fig. 8. BBA5P: Pessimistic Second Combination. The labels along the top of the cells are the lower bounds on $\theta$, and those down the left hand side are the upper bounds. The range of values indicated by a given cell is the combination of its lower column bound and its upper row bound. Thus the top left hand cell corresponds to $0 \leq \theta \leq 1$, and the cell in the second column of the third row corresponds to $0.004 \leq \theta \leq 0.018$.

The second refinement is that of dealing with the dependencies between the pieces of evidence. One of the restrictions of Dempster's rule of combination for updating beliefs is that it assumes the the sources of the mass distributions being combined are distinct. Within the transferable belief model [87] this means, broadly speaking, that the mass distributions do not use any common information. This has led to many people being under the impression that belief functions can only be deployed in situations in which the various mass distributions are distinct, and therefore ruling out the possibility of using belief functions to model situations where there are known dependencies between the various sources of evidence (the kind of situations which are neatly handled by Bayesian networks [72]). However, this is not true. It is perfectly possible to build models using belief functions which deal with non-distinct mass distributions, provided one takes the non-distinctness into account in the appropriate way. One particularly attractive way of doing this is suggested by $\mathrm{Xu}$ and Smets [112], who introduce an approach which has much in common with Bayesian networks. Methods based on the ShenoyShafer hypertree computation approach [81] can also be used to deal with the problem.

\section{Conclusions}

This article has described an application of belief functions to forecasting demand for a new telecommunications service, Global Mobile Satellite Services. 
Although the model presented here has been simplified, and disguised rather than real numbers have been used, we believe the example has demonstrated the power of the TBM for demand forecasting in uncertain environments. Demand estimation for a new high-technology product or service category is often a situation of "near ignorance", both for intending operators and for their prospective customers. In such circumstances, belief functions enable uncertainty to be represented appropriately and prevent an unwarranted precision being inserted into or perceived in market forecasts.

In addition, the theory provides a coherent mechanism for combining new evidence with existing forecasts, on an on-going basis, essential in an environment with the long lead times between project commencement and the launch of commercial service seen in the MSS industry. It has benefits over alternative approaches to demand forecasting which require information on a past which may be non-existent or irrelevant (as is the case with time series analysis and econometric methods) or which require explicit and agreed knowledge of a very uncertain future (as is the case with Structured Scenario Analysis).

Moreover, the transferable belief model permits the assignment of a portion of the total belief mass to values of the forecast parameters which are considered highly unlikely but are still believed possible. In this way it ensures that the uncertainty inherent in any forecaster's view of the future is represented, and is not supressed through quantification and summarization. Indeed, as this example has demonstrated, the TBM even permits the formal representation of doubt in a view of the future which is otherwise predominantly optmistic or predominantly pessimistic. For the reasons presented here, then, we believe that belief functions have considerable potential for application in highly-uncertain business domains, such as in the forecasting of demand for new products and services.

This application demonstrated the assignment of belief values to intervals of an unknown parameter. At the earliest stages of planning of new products or services, however, uncertainty regarding market potential may be so great as to preclude the assignment of numeric values to unknown parameters, even when expressed as intervals. Stakeholders in such circumstances may only be comfortable assigning linguistic or qualitative labels to such intervals. One area worthy of further investigation, then, is the application of qualitative and linguistic belief function approaches to demand forecasting. Some of the theory for such an approach has already been developed $[66,67,70]$, and is a topic of further exploration by the authors.

\section{Acknowledgments}

The work reported herein was motivated by consultancy projects undertaken by the authors for two intending global satellite network operators, and we wish to thank our anonymous clients for the opportunities we have had to 
work with them. This work has been partly supported by the British Engineering and Physical Sciences Research Council (EPSRC), under grant GR/L84117 and a PhD studentship, and this support is also appreciated. We are also grateful to Philippe Smets for detailed comments on an earlier draft of this paper.

\section{References}

1. D. A. Aaker, V. Kumar, and G. S. Day. Marketing Research. John Wiley and Sons, New York City, NY, USA, 1995.

2. K. Altinkemer, W. T. Yue, and L. Yu. Adoption of Low Earth Orbit satellite system: a diffusion model under competition. In Proceedings of the rth International Conference on Telecommunications Systems Modeling and Analysis, pages 339-355, Nashville, TN, USA, 1999. American Telecommunications Systems Management Association.

3. Austel. Public Mobile Telecommunications Services. Report to the Minister of Transport and Communications, Australian Telecommunications Authority, Commonwealth of Australia, Melbourne, Australia, 1990.

4. F. M. Bass. A new product growth model for consumer durables. Management Science, 15:215-227, 1969.

5. Booz, Allen and Hamilton. New Product Management for the 1980s. Report, Booz, Allen and Hamilton, New York City, NY, USA, 1982.

6. I. Brodsky. Wireless: The Revolution in Personal Telecommunications. Artech House Publishers, Boston, MA, USA, 1995.

7. G. Calhoun. Digital Cellular Radio. Artech House, Norwood, MA, USA, 1988.

8. J. Cano, S. Moral, and J. F. Verdegay López. Combination of lower and upper probabilities. In Proceedings of the 7th Conference on Uncertainty in AI, Los Angeles., 1991.

9. W. F. Caselton and W. Luo. Decision making with imprecise probabilities: Dempster-Shafer Theory and application. Water Resources Research, 28 (12):3071-3083, 1992.

10. W. F. Caselton and W. Luo. Inference and decision under near ignorance conditions. In L. Duckstein and E. Parent, editors, Engineering Risk in Natural Resources Management, pages 291-304. Kluwer Academic (NATO Advanced Study Institute Series), 1994.

11. D. Casley and D. A. Lury. Data Collection in Developing Countries. Oxford University Press, Oxford UK, 1981.

12. L. Cauley. ICO Global satellite-phone venture, affiliates, seek bankruptcy protection. Wall Street Journal, 30 August 1999.

13. L. Cauley. Iridium seeks bankruptcy protection after bondholders submit petition. Wall Street Journal, 16 August 1999.

14. L. Cauley. Iridium's phone marketing took a back seat to science. Wall Street Journal, page 1, 18 August 1999.

15. H. Courtney, J. Kirkland, and P. Viguerie. Strategy under uncertainty. Harvard Business Review, 75 (6):66-79, 1997.

16. A. P. Dempster. Upper and lower probabilities induced by a multi-valued mapping. Annals of Mathematical Statistics, 38:325-339, 1967. 
17. T. Denoeux. A k-nearest neighbour classification rule based on DempsterShafer theory. IEEE Transactions on Systems, Man, and Cybernetics, 25:804$813,1995$.

18. A. F. Dragoni and P. Giorgini. Sensor data validation for nuclear power plants through Bayesian conditioning and Dempster's rule of combination. Computers and Artificial Intelligence, 17:151-168, 1998.

19. R. Dusenbury, J. L. Reimers, and S. Wheeler. An empirical study of beliefbased and probability-based specifications of audit risk. Auditing: A Journal of Practice and Theory, 15 (2):12-28, 1996.

20. A. L. Evans, J. S. Rose, and R. Venkataraman. The future of satellite communicating. The McKinsey Quarterly, 2:7-17, 1998.

21. D. Fost. Globalstar stock crashes with rocket. San Francisco Chronicle, 11 September, 1998.

22. B. Frank. Internationale Entwicklungsmuster zellularen Mobilfunks. In J. Kruse, editor, Zellularer Mobilfunk: Neue Märkte mit neuen Netzen für das Funktelefon, pages 271-281. R. v. Decker's Verlag, G. Schenk, Heidelberg, Germany, 1992.

23. J. Gardiner. The role of satellites in PCS. In J. Gardiner and B. West, editors, Personal Communications Systems and Technologies, pages 145-167. Artech House Publishers, Boston, MA, UK, 1995.

24. T. Goren. Will Iridium losses sink Motorola? Dow Jones Newswires, 25 May 1999.

25. P. E. Green and A. M. Krieger. Conjoint analysis with product-positioning applications. In J. Eliashberg and G. L. Lilien, editors, Handbooks in Operations Research and Management Science, Volume 5: Marketing, pages 467516. North-Holland, Amsterdam, The Netherlands, 1993.

26. P. E. Green, D. S. Tull, and G. Albaum. Research for Marketing Decisions, Fifth Edition. Prentice-Hall, Englewood Cliffs, NJ, USA, 1988.

27. M. Gruszecki and R. N. Andries. Some new concepts in demand and traffic forecasting and planning of future telecommunications services. Computer Networks and ISDN Systems, 20 (1-5):65-74, 1990.

28. J. W. Guan and D. A. Bell. Evidence theory and its applications. North Holland, Amsterdam, The Netherlands, 1991.

29. A. D. Hadden. Personal Communications Networks: Practical Implementation. Artech House Publishers, Boston, MA, USA, 1995.

30. J.Y. Halpern and R. Fagin. Two views of belief: belief as generalized probability and belief as evidence. Artificial Intelligence, 54:275-317, 1992.

31. D. P. Hamilton. Iridium LLC's Chief Executive quits abruptly. Wall Street Journal, page B8, 23 April 1999.

32. Q. Hardy. How a wife's question led Motorola to chase global cell-phone plan. Wall Street Journal, page 1, 16 December 1996.

33. Q. Hardy. Iridium creates new plan for global cellular service. Wall Street Journal, 18 August 1997.

34. Q. Hardy. Iridium delays commercial phone links. Wall Street Journal, page A3, 9 September 1998.

35. Q. Hardy. Iridium is set to launch call service but concerns mount over performance. Wall Street Journal, page B8, 28 October 1998.

36. Q. Hardy. Global-minded Iridium has down-to-earth need: Profit. Wall Street Journal, page B4, 26 January 1999. 
37. Q. Hardy. Iridium says it expects to miss targets for subscribers, revenue in 1st Quarter. Wall Street Journal, page B6, 1 March 1999.

38. P. Hemming, D. P. Shuker, and P. J. McBurney. Innovative PCS Marketing: How to Build and Execute a Winning Marketing Plan. Redwing Consulting Ltd, Dallas, TX, USA, 1996.

39. ICO. ICO Facts. ICO Global Communications Ltd, Hammersmith, London, UK, March 1999.

40. M. A. Jolson and G. L. Rossow. The Delphi approach in marketing decision making. Journal of Marketing Research, 8:443-448, 1971.

41. T. Kelly. Forecasting the mobile communications market: A finger in the airwaves? Paper presented at Conference on Market Forecasting in the Telecoms Industry, Hong Kong, International Telecommunications Union, Geneva, Switzerland, March 1996.

42. J. Kohlas and P. A. Monney. A Mathematical Theory of Hints: An Approach to Dempster Shafer Theory of Evidence. Springer Verlag (Lecture Notes in Economics and Mathematical Systems), Berlin, Germany, 1995.

43. S. Koreisha and R. Stobaugh. Limits to models. In R. Stobaugh and D. Yergin, editors, Energy Future: Report of the Energy Project of the Harvard Business School, pages 234-265. Random House, New York City, NY, USA, 1979.

44. P. Kotler. Marketing Management: Analysis, Planning, Implementation and Control. Prentice-Hall, Englewood Cliffs, NJ, USA, 1991.

45. D. J. Kridel and D. R. Dolk. Modeling telecommunications demand analysis. Interfaces, 23 (2):3-13, 1993.

46. J. Kruse. Lizenzierung und Wettbewerb im Mobilfunk. Springer Verlag, Berlin, Germany, 1993.

47. J. M. Kushner. Market research in a non-Western context: The Asian example. Journal of the Market Research Society, 24:116-122, 1982.

48. M. Lalmas. Information retrieval and Dempster-Shafer's theory of evidence. In A. Hunter and S. Parsons, editors, Applications of Uncertainty Formalisms, pages 157-176. Springer Verlag (LNAI 1455), Berlin, Germany, 1998.

49. K. J. Lancaster. A new approach to consumer theory. Journal of Political Economy, 74:132-157, 1966.

50. K. J. Lancaster. Consumer Demand: A New Approach. Columbia University Press, New York City, NY, USA, 1971.

51. J. C. Lee. Nested Rotterdam Model: Applications to marketing research with special reference to telecommunications demand. International Journal of Forecasting, 4:193-206, 1988.

52. W. C. Y. Lee. Mobile Cellular Telecommunications Systems. McGraw-Hill, New York City, NY, USA, 1989.

53. T. Levitt. Exploit the Product Life Cycle. Harvard Business Review, 43 (6):81-94, 1965.

54. G. L. Lilien, P. Kotler, and K. S. Moorthy. Marketing Models. Prentice-Hall, Englewood Cliffs, NJ, USA, 1992.

55. W. B. Luo and B. Caselton. Using Dempster-Shafer Theory to represent climate change. Journal of Environmental Management, 49:73-93, 1997.

56. V. Mahajan, E. Muller, and F. M. Bass. New-product diffusion models. In J. Eliashberg and G. L. Lilien, editors, Handbooks in Operations Research and Management Science, Volume 5: Marketing, pages 349-408. North-Holland, Amsterdam, The Netherlands, 1993. 
57. G. Maral and M. Bousquet. Satellite Communications Systems: Systems, Techniques and Technology, Third Edition. John Wiley and Sons, Chichester, UK, 1998.

58. P. McBurney and M. Dobbin. Prospects for Australian Participation in LBand Mobile Satellite Communications: A Report for the Australian Department of Industry, Technology and Commerce (DITAC). Consultancy report, BIS Shrapnel Pty. Ltd., Sydney, Australia, 1989.

59. P. McBurney, J. Green, and S. Parsons. Forecasting demand for new telecommunications services: an introduction. Technical report, Department of Electronic Engineering, Queen Mary and Westfield College, University of London, Mile End, London, UK, 1999.

60. P. McBurney and D. Shuker. The World Avionics Market: A Report for the Australian Department of Industry, Technology and Commerce (DITAC). Consultancy report, BIS Shrapnel Pty. Ltd., Sydney, Australia, 1990.

61. P. J. McBurney. On transferring statistical techniques across cultures: The Kish Grid. Current Anthropology, 29 (2):323-325, 1988.

62. D. F. Midgley. Innovation and New Product Marketing. Croom Helm, London, UK, 1977.

63. G. A. Moore. Crossing the Chasm: Marketing and Selling High-Tech Products to Mainstream Consumers. HarperCollins, New York City, NY, USA, 1991.

64. H. P. Nii. Blackboard systems (part one): the blackboard model of problem solving and the evolution of blackboard architectures. The AI Magazine, Summer:38-53, 1986.

65. S. Parsons. Using interval algebras to model order of magnitude reasoning. Artificial Intelligence in Engineering, 8 (2):87-98, 1993.

66. S. Parsons. Some qualitative approaches to applying the Dempster-Shafer theory. Information and Decision Technologies, 19:321-337, 1994.

67. S. Parsons. Qualitative Approaches to Reasoning Under Uncertainty. MIT Press (to appear), Cambridge, MA, USA, 1999.

68. S. Parsons, T. Brown, S. King, and E. H. Mamdani. A blackboard system for active decision support in configuring telecommunications services. In Proceedings of the 13th International Conference on Artificial Intelligence, Expert Systems and Natural Language, Avignon, France, 1993.

69. S. Parsons and P. Giorgini. An approach to using degrees of belief in BDI agents. In B. Bouchon-Meunier, R. R. Yager, and L. A. Zadeh, editors, Information, Uncertainty, Fusion. Kluwer, Dordrecht, 1999.

70. S. Parsons and E. H. Mamdani. Qualitative Dempster-Shafer Theory. In Proceedings of the Third EMACS International Workshop on Qualitative Reasoning and Decision Technologies, Barcelona, Spain, 1993.

71. B. Pattan. Satellite-Based Global Cellular Communications. McGraw-Hill, New York City, NY, USA, 1998.

72. J. Pearl. Probabilistic Reasoning in Intelligent Systems: Networks of Plausible Inference. Morgan Kaufmann, Palo Alto, CA, 1988.

73. J. Pearl. Reasoning with belief functions: an analysis of compatibility. International Journal of Approximate Reasoning, 4:363-389, 1990.

74. J. Picard. Two applications of probabilistic argumentation systems to information retrieval. In Proceedings of the Workshop on Logical and Uncertainty Models for Information Systems. European Conference on Symbolic and Quantitative Approaches to Reasoning and Uncertainty, London, 1999. 
75. H. Pope and Q. Hardy. Glitches surface as Iridium phones go to war. Wall Street Journal, page B1, 27 April 1999.

76. H. Raiffa. Decision Analysis: Introductory Lectures on Choices under Uncertainty. Addison-Wesley, Reading, MA, 1970.

77. S. Rhinds. Globalstar expects break-even results in first full year. Wall Street Journal, page B5B, 26 February 1999.

78. E. M. Rogers. Diffusion of Innovations, Third Edition. The Free Press, New York City, NY, USA, 1983.

79. A. Saffiotti, S. Parsons, and E. Umkehrer. A case study in comparing uncertainty management techniques. Microcomputers in Civil Engineering: Special Issue on Uncertainty in Expert Systems, 9:367-380, 1994.

80. G. Shafer. A Mathematical Theory of Evidence. Princeton University Press, Princeton, NJ, USA, 1976.

81. G. Shafer, P. P. Shenoy, and K. Mellouli. Propagating belief functions in qualitative Markov trees. International Journal of Approximate Reasoning, 1:349-400, 1987.

82. G. Shafer and R. P. Srivastava. The Bayesian and Belief-Function formalisms - a general approach for auditing. Auditing-A Journal of Practice and Theory, 9:110-137, 1990.

83. P. Smets. Belief functions. In P. Smets, A. Mamdani, D. Dubois, and H. Prade, editors, Non-Standard Logics for Automated Reasoning, pages 253-286. Academic Press, London, UK, 1988.

84. P. Smets. The transferable belief model for expert judgments and reliability problems. Reliability Engineering and System Safety, 38:59-66, 1992.

85. P. Smets. Quantifying beliefs by belief functions: an axiomatic justification. In Proceedings of the 13th International Joint Conference on Artificial Intelligence, pages 598-603, San Mateo, CA, 1993. Morgan Kaufmann.

86. P. Smets. Application of the transferable belief model to diagnostic problems. International Journal of Intelligent Systems, 13:127-157, 1998.

87. P. Smets. The transferable belief model for quantified belief representation. In D. M. Gabbay and P. Smets, editors, Handbook of Defeasible Reasoning and Uncertainty Management Systems, Vol. 1, pages 267-301. Kluwer, Doordrecht, The Netherlands, 1998.

88. P. Smets. Practical uses of belief functions. In Proceedings of the 14th Conference on Uncertainty in Artificial Intelligence, Stockholm, Sweden, 1999.

89. P. Smets and R. Kennes. The transferable belief model. Artificial Intelligence, 66:191-234, 1994.

90. P. Smets and R. Kruse. The transferable belief model for quantified belief representation. In A. Motro and P. Smets, editors, Uncertainty in Information Systems: From Needs to Solutions, pages 343-368. Kluwer, Boston, MA, 1997.

91. R. P. Srivastava. The Belief-Function approach to aggregating audit evidence. International Journal of Intelligent Systems, 10:329-356, 1995.

92. R. P. Srivastava. Audit decisions using belief functions: a review. Control and Cybernetics, 26 (2):135-160, 1997.

93. R. P. Srivastava. Decision making under ambiguity: a belief function perspective. Archives of Control Sciences, 6 (1-2):5-27, 1997.

94. R. P. Srivastava and G. Shafer. Integrating statistical and non-statistical audit evidence using belief functions: a case of variable sampling. International Journal of Intelligent Systems, 9:519-539, 1994. 
95. J. L. Stanton, R. Chandran, and S. A. Hernandez. Marketing research problems in Latin America. Journal of the Market Research Society, 24:124-139, 1982.

96. P. L. Stepankowsky. Teledesic looks to avoid problems that hurt other satellite providers. Wall Street Journal, 3 September 1999.

97. A. Stepick and C. D. Stepick. People in the shadows: survey research among Haitians in Miami. Human Organization, 49 (1):64-77, 1990.

98. L. D. Taylor. Telecommunications Demand: A Survey and Critique. Ballinger Publishing, Cambridge, MA, USA, 1980.

99. UMTS Forum. The Future Mobile Market: Global trends and developments with a focus on Western Europe. Report 8, Universal Mobile Telecommunications Services Forum, London, UK, 1999.

100. G. L. Urban and J. R. Hauser. Design and Marketing of New Products. Prentice-Hall, Englewood Cliffs, NJ, USA, 1993.

101. G. L. Urban, J. R. Hauser, and J. H. Roberts. Prelaunch forecasting of new automobiles. Management Science, 36 (4):401-421, 1990.

102. G. L. Urban, B. D. Weinberg, and J. R. Hauser. Premarket forecasting really new products. Journal of Marketing, 60 (1):47-60, 1996.

103. K. van Dam. Using uncertainty techniques in radio communications systems. In A. Hunter and S. Parsons, editors, Applications of Uncertainty Formalisms, pages 76-87. Springer Verlag (LNAI 1455), Berlin, Germany, 1998.

104. C. Van den Acker and J. Vanthienen. Integrating statistical audit evidence with belief function theory. In Proceedings of the First International Conference on Formal and Applied Reasoning, pages 1-14, 1996.

105. G. Walsham. A model of future telecommunications demand. Journal of the Operational Research Society, 33:A34, 1982.

106. I. R. Weatherford and S. E. Bodily. A taxonomy and research overview of perishable-asset revenue management: Yield management, pricing, and overbooking. Operations Research, 40:831-844, 1992.

107. R. Wetenhall. Propagation delay - an MSS red herring. Mobile Communications International, page 25, June 1998.

108. D. Wilson, A. Grieg, J. Gilbey, and R. Smith. Some problems in trying to implement uncertainty techniques in automated inspection. In A. Hunter and S. Parsons, editors, Applications of Uncertainty Formalisms, pages 225-241. Springer Verlag (LNAI 1455), Berlin, Germany, 1998.

109. D. R. Wittink and P. Cattin. Commercial use of conjoint analysis: An update. Journal of Marketing, 53:91-96, 1989.

110. WSJ. Iridium reaches debt waiver as it struggles to win customers. Wall Street Journal, 1 June 1999.

111. H. Xu, Y. T. Hsia, and P. Smets. Transferable Belief Model for decision making in valuation-based systems. IEEE Transactions on Systems, Man, and Cybernetics, 26A:698-707, 1996.

112. H. Xu and P. Smets. Evidential reasoning with conditional belief functions. In Proceedings of the 10th Conference on Uncertainty in Artificial Intelligence, pages 598-605, San Francisco, CA, 1994. Morgan Kaufmann.

113. M. D. Yacoub. Cell design principles. In J. D. Gibson, editor, The Mobile Communications Handbook, Second Edition, chapter 21. CRC Press and Springer Verlag, Boca Raton, FL, USA, 1999.

114. L. A. Zadeh. Fuzzy probabilities. Information Processing \& Management, 3:363-372, 1984. 